\title{
Intracellular calcium transients underlying interval-force relationship in whole rat hearts: effects of calcium antagonists
}

\author{
Christian E. Zaugg ${ }^{\text {a, }}$, Shoji Kojima ${ }^{a}$, Shao T. Wu a, Joan Wikman-Coffelt ${ }^{\text {a }}$, \\ William W. Parmley ${ }^{a}$, Peter T. Buser ${ }^{b}$ \\ ${ }^{a}$ Department of Medicine and Cardiovascular Research Institute, University of California San Francisco, San Francisco, CA 94143, USA \\ ${ }^{\mathrm{b}}$ Division of Cardiology, Department of Medicine, University Hospitals, Basel, Switzerland
}

Received 9 December 1994; accepted 27 March 1995

\begin{abstract}
Objectives: Much of the understanding about the cardiac interval-force relationship of the whole heart, including mechanical restitution and postextrasystolic potentiation (PESP), has been inferred from isolated muscle studies. We tested whether results from isolated muscles about intracellular $\mathrm{Ca}^{2+}\left(\left[\mathrm{Ca}^{2+}\right]_{\mathrm{i}}\right)$ transients underlying the interval-force relationship can be substantiated in whole hearts. Additionally, we investigated whether $\mathrm{Ca}^{2+}$ antagonists could alter $\left[\mathrm{Ca}^{2+}\right]_{i}$ transients underlying mechanical restitution and postextrasystolic potentiation. Methods: $\left[\mathrm{Ca}^{2+}\right]_{\mathrm{i}}$ transients were studied in isollated perfused rat hearts by surface fluorometry and Indo-1. Using computer-controlled pacing protocols, we performed restitution curves for left ventricular developed pressure and [Ca $\left.{ }^{2+}\right]$ (developed pressure and $\left[\mathrm{Ca}^{2+}\right]_{\mathrm{i}}$ plotted as a function of extrasystolic intervals). To quantify restitution curves, we fitted monoexponential functions to plots and analyzed their shift and slope. Then, we used $\mathrm{Ca}^{2+}$ antagonists, low extracellular $\mathrm{Ca}^{2+}\left(\left[\mathrm{Ca}^{2+}\right]_{0}\right)$ and PESP to modify restitution curves. $\left[\mathrm{Ca}^{2+}\right]_{\mathrm{i}}$ transients in isolated rat hearts were interpreted as $\mathrm{Ca}^{2+}$ released from the sarcoplasmic reticulum. Results: Interval-dependent changes in developed pressure were strongly correlated to interval-dependent changes in the amplitude of $\left[\mathrm{Ca}^{2+}\right]_{\mathrm{i}}$ transients in isolated whole rat hearts. Additionally, nifedipine and low $\left[\mathrm{Ca}^{2+}\right]_{0}$ led to similar downward shifts but not to a changed slope of restitution curves for $\left[\mathrm{Ca}^{2+}\right]_{\mathrm{i}}$. On the other hand, PESP increased the slope of restitution curves for $\left[\mathrm{Ca}^{2+}\right]_{\mathrm{i}}$. Furthermore, the effect of PESP on developed pressure was blunted by high concentrations of $\mathrm{Ca}^{2+}$ antagonists. Conclusions: The results from isolated muscles about $\left[\mathrm{Ca}^{2+}\right]_{\mathrm{i}}$ transients underlying the interval-force relationship could be substantiated in whole hearts. Additionally, low $\left[\mathrm{Ca}^{2+}\right]_{j}$ (induced by nifedipine $\omega$ r low $\left[\mathrm{Ca}^{2+}\right]_{\mathrm{o}}$ ) decreased the maximal $\mathrm{Ca}^{2+}$ release of the sarcoplasmic reticulum but did not change the release kinetics. On the other hand, PESP presumably accelerated $\mathrm{Ca}^{2+}$ release kinetics of the sarcoplasmic reticulum.
\end{abstract}

Keywords: Interval-force relationship; Postextrasystolic potentiation; Calcium intracellular concentration; Calcium antagonists; Indo-1; Surface fluorometry; Rat heart; Calcium transients

\section{Introduction}

Cardiac contractile force is closely related to time intervals between heart beats. This interval-force relationship includes two properties of cardiac muscle, described as mechanical restitution [1] and postextrasystolic potentiation [2]. The first property, mechanical restitution, describes the recovery of myocardial contractility during the interval between heart beats. Mechanical restitution is studied experimentally by the mechanical restitution curve which represents a plot of the cardiac force as a function of increasing time intervals between heart beats. The second cardiac property, postextrasystolic potentiation, de-

\footnotetext{
* Corresponding author. M-1186, Cardiology Division, University of California San Francisco, 505 Parnassus, San Francisco, CA 94143-0124, USA. Tel.: 415-476-1710; Fax 415-476-0424.
}

scribes the force of the first contraction after a premature beat. Both of these properties have been widely studied in various species and interval-dependent changes in the amplitucle of intracellular $\mathrm{Ca}^{2+}\left(\left[\mathrm{Ca}^{2+}\right]_{\mathrm{i}}\right)$ transients were shown to be responsible for the interval-dependent changes in the force of contraction [for review, see Ref. 3]. So far, much of the understanding about the interval-force relationship of the whole heart has been inferred from isolated muscle studies. Moreover, all studies involving measurements of $\left[\mathrm{Ca}^{2+}\right]_{i}$ transients were performed in isolated muscle preparations. However, certain disadvantages are related to isolated muscle preparations. First, a fast physiological pacing rate can not be used in isolated muscle preparations because of potential central ischemia [4]. Second, in isolated muscles, recirculating activator $\mathrm{Ca}^{2+}$ and

Time for primary review 42 days. 
$\mathrm{Ca}^{2+}$ entering during the action potential might contribute differently to $\left[\mathrm{Ca}^{2+}\right]_{i}$ transients than in whole hearts [5]. Therefore, an isolated heart would be a more nearly physiological preparation to study $\left[\mathrm{Ca}^{2+}\right]_{i}$ transients underlying the interval-force relationship. Furthermore, measurements of $\left[\mathrm{Ca}^{2+}\right]_{i}$ transients in an isolated rat heart primarily reflect sarcoplasmic reticulum function because in rat myocardium, peculiarly $90 \%$ of the $\left[\mathrm{Ca}^{2+}\right]_{i}$ transients are composed of $\mathrm{Ca}^{2+}$ released from the sarcoplasmic reticulum [6]. Consequently, the contribution of the sarcoplasmic reticulum to restitution and postextrasystolic potentiation as well as drug effects on this contribution could be studied in isolated whole rat hearts.

The aim of the present study was to test whether the results from isolated muscle preparations about $\left[\mathrm{Ca}^{2+}\right]_{i}$ transients underlying the interval-force relationship can be substantiated in whole hearts. For this purpose, we studied $\left[\mathrm{Ca}^{2+}\right]_{i}$ transients in isolated perfused rat hearts by surface fluorometry and Indo-1. Using computer-controlled pacing protocols we generated restitution curves for left ventricular developed pressure and, simultaneously, for $\left[\mathrm{Ca}^{2+}\right]_{\mathrm{i}}$ transients. In addition, we sought to evaluate the sarcoplasmic reticulum function involved in mechanical restitution and postextrasystolic potentiation in whole rat hearts. For this purpose, we used $\mathrm{Ca}^{2+}$ antagonists and postextrasystolic potentiation to modify the restitution curves. Because $\mathrm{Ca}^{2+}$ antagonists have been proposed to alter sarcoplasmic reticulum function $[7,8]$, we also investigated whether such an effect could alter $\left[\mathrm{Ca}^{2+}\right]_{i}$ transients underlying mechanical restitution and postextrasystolic potentiation. For this purpose, we compared the effects of $\mathrm{Ca}^{2+}$ antagonists and low extracellular $\mathrm{Ca}^{2+}\left(\left[\mathrm{Ca}^{2+}\right]_{0}\right)$ on restitution curves for $\left[\mathrm{Ca}^{2+}\right]_{i}$ transients.

\section{Methods}

\subsection{Animals}

Sprague-Dawley rats, weighing 450-500 g, were used in the present study. The animal use protocol was approved by the Animal Research Committee of the University of California San Francisco.

\subsection{Perfused heart model}

After ether anesthesia, hearts were excised rapidly through a midline sternotomy and perfused at $36^{\circ} \mathrm{C}$ within 30-60 s according to a modified Langendorff method [9-11]. All hearts were perfused at a perfusion pressure of $110 \mathrm{~cm} \mathrm{H}_{2} \mathrm{O}$ with a modified Krebs-Henseleit solution containing $117.0 \mathrm{mM} \mathrm{NaCl}, 4.3 \mathrm{mM} \mathrm{KCl}, 1.80,1.00$, or $0.55 \mathrm{mM} \mathrm{CaCl}, 1.2 \mathrm{mM} \mathrm{MgSO}_{4}, 25.0 \mathrm{mM} \mathrm{NaHCO}$, $0.25 \mathrm{mM}$ NaEDTA and $15 \mathrm{mM}$ glucose. Free $\mathrm{Ca}^{2+}$ concentrations in the perfusate $\left(\left[\mathrm{Ca}^{2+}\right]_{0}\right.$ concentrations) were estimated to be $1.55,0.75$, and 0.30 with $1.80,1.00$, and $0.55 \mathrm{mM} \mathrm{CaCl}_{2}$ according to the multiequilibrium calculation developed by Perrin and Sayce [12]. The perfusate was saturated with a gas mixture of $95 \% \mathrm{O}_{2}$ and $5 \% \mathrm{CO}_{2}$.
To dissolve maximum oxygen the temperature of the perfusate was raised subsequently from $25^{\circ} \mathrm{C}$ to $36^{\circ} \mathrm{C}$. This procedure resulted in an oxygen tension of the perfusate between 500 and $600 \mathrm{~mm} \mathrm{Hg}$ and a pH of 7.4. In order to create atrioventricular block, the interatrial septum was incised through an approach via the right atrial appendage. The incision was patched with a surgical suture to ensure accurate pressure measurement. Then, a pair of platinum pacemaker wires from a computer-controlled pulse generator (Medtronic model 5320) were implanted in the left ventricular free wall and the hearts were stimulated at a steady-state frequency of $3.3 \mathrm{~Hz}(300 \mathrm{~ms}$ steady-state interval). A bipolar electrocardiogram (ECG) was recorded from electrodes implanted in the right atrium and the apex.

\subsection{Pacing protocols}

The isolated perfused rat hearts underwent two preprogrammed pacing protocols that were consecutively generated by the computer-controlled pulse generator. To obtain restitution curves $(\mathrm{RC})$, the first pacing protocol introduced extrasystolic beats at different extrasystolic intervals which varied from 120 to $860 \mathrm{~ms}(120,180,240,300,360,420$, $480,540,600,660,720$, and $860 \mathrm{~ms})$. In the second pacing protocol, extrasystolic beats at different extrasystolic intervals from 120 to $860 \mathrm{~ms}(120,180,240,300$, $360,420,480,540,600,660,720$, and $860 \mathrm{~ms}$ ) were introduced after a premature beat which was triggered 120 $\mathrm{ms}$ after a steady-state beat. Thus, the second pacing protocol led to postextrasystolic restitution curves (PESRC) and allowed us to investigate the effect of postextrasystolic potentiation on restitution curves. During both pacing protocols, hearts were allowed to return to steadystate values before a new extrasystole was introduced.

\subsection{Experimental protocol}

All hearts underwent the two pacing protocols for restitution curves and postextrasystolic restitution curves repeatedly during different perfusion conditions (all at $36^{\circ} \mathrm{C}$ ). First, both pacing protocols were performed during control perfusion $\left(1.55 \mathrm{mM}\left[\mathrm{Ca}^{2+}\right]_{0}\right)$. Then, they were repeated during perfusion with different concentrations of nifedipine, verapamil, diltiazem $\left(1.55 \mathrm{mM}\left[\mathrm{Ca}^{2+}\right]_{0}\right)$ or perfusate containing low $\mathrm{Ca}^{2+}$ (to produce low $\left[\mathrm{Ca}^{2+}\right]_{0}$ ). The same hearts were perfused with two different $\mathrm{Ca}^{2+}$ antagonists (on condition that the first treatment was reversible). Verapamil was always the final treatment. Controls were performed for each perfusion condition (for each of the three $\mathrm{Ca}^{2+}$ antagonists and for low $\left[\mathrm{Ca}^{2+}\right]_{0}$ ).

During the two pacing protocols for restitution curves and postextrasystolic restitution curves, simultaneous measurements of left ventricular developed pressure (LVDP) and $\left[\mathrm{Ca}^{2+}\right]_{\mathrm{i}}$ were performed under different perfusion conditions. Developed pressure was measured for all perfusion conditions (control, three different concentrations of all three $\mathrm{Ca}^{2+}$ antagonists and two different concentrations of low $\left[\mathrm{Ca}^{2+}\right]_{0}$ ). Because all three $\mathrm{Ca}^{2+}$ antagonists led to very similar responses of developed pressure during the pacing protocols, $\left[\mathrm{Ca}^{2+}\right]_{i}$ was measured only for three 
selected perfusion conditions (control, $1.00 \mu \mathrm{M}$ nifedipine and $0.30 \mathrm{mM}\left[\mathrm{Ca}^{2+}\right]_{0}$ ).

\subsection{Measurements of left ventricular pressure}

A $500 \mu 1$ thin latex balloon was inserted into the left ventricle through the left atrium. Left ventricular developed pressure (difference in systolic and diastolic values) was measured by a plastic tube located inside the balloon, sutured at the proximal end of the balloon, and connected to a Statham P23 Db pressure transducer (Gould, Cleveland, $\mathrm{OH}$ ). The volume of the saline-filled balloon was adjusted with a calibrated microsyringe through a three-way stopcock contained in this plastic tube to establish a constant physiological end-diastolic pressure in the range of $5-10 \mathrm{~mm} \mathrm{Hg}$. Thus, the left ventricle contracted isovolumically throughout the experiment.

\subsection{Measurements of $\left[\mathrm{Ca}^{2+}\right]_{i}$ by surface fluorometry and Indo-1}

Fluorescence excitation was provided by ultraviolet light from a $100 \mathrm{~W}$ mercury vapor lamp. The ultraviolet light was directed through a $365 \pm 10 \mathrm{~nm}$ discriminating filter and a custom-made silica fiberoptic cable, designed to assess excitation and emission simultaneously on a 38.5 $\mathrm{mm}^{2}$ circular area of the cardiac surface [9-11]. The emitted fluorescence was sensed by a co-axial cable of 300 quartz fiberoptics, divided by a beam splitter, and then filtered at $400 \pm 5$ and $510 \pm 12.5 \mathrm{~nm}$ before reaching the photomultiplier tubes. Photomultiplier output at 400 and $510 \mathrm{~nm}$ and its ratio $\mathrm{F} 400 / \mathrm{F} 510$, an index of $\left[\mathrm{Ca}^{2+}\right]_{\mathrm{i}}$, were recorded on a 6-channel dynograph (Gould, Cleveland, $\mathrm{OH}$ ) simultaneously with the left ventricular pressure and the ECG. To place the fiberoptic on the interventricular septum, the tip of the fiberoptic was inserted through a circular cut in the right ventricular free wall and fixed firmly on the right ventricular side of the interventricular septum. This approach of the fiberoptic through a hole in the right ventricular wall does not interfere with left ventricular or septal perfusion because the right ventricular coronary artery does not supply the left ventricular wall or the interventricular septum in rat hearts [13]. Firm contact between the optic fiber and cardiac surface was required to obtain a reliable signal. Because forceful compression by the fiberoptic could cause changes in the shape of the left ventricle and alterations in myocardial perfusion, the placement of the fiberoptic was confirmed not to change developed pressure more than $5 \%$ of the control value.

The fluorometer was offset for autofluoroscence (400 and $510 \mathrm{~nm}$ ) of the heart [14]. Then, the hearts were loaded with the cell-permeable fluorescent dye Indo-1 acetoxymethylester by perfusion for $60 \mathrm{~min}$. This perfusate consisted of $16 \mathrm{mg}$ of Indo-1 acetoxymethylester dissolved in $1 \mathrm{ml}$ of dimethylsulfoxide and $600 \mathrm{ml}$ of Krebs-Henseleit containing $5 \%$ calf serum. Indo-1 loading was facilitated by perfusion at $30^{\circ} \mathrm{C}$ [15] and was followed by $30 \mathrm{~min}$ washout at $36^{\circ} \mathrm{C}$. This procedure of Indo-1 loading led to fluorescence readouts of approximately $1 \mathrm{~V}$ at both 400 $\mathrm{nm}$ and $510 \mathrm{~nm}$ (autofluorescence approximately $0.08 \mathrm{~V}$ ).

\subsection{Limitation and evaluation of $\left[\mathrm{Ca}^{2+}\right]_{i}$ measurement by surface fluorometry and Indo-1}

Some limitations and their consequences on the evaluation of the surface fluorometry technique with Indo-1 have to be cited. A possible limitation includes sequestration of Indo-1 in mitochondria potentially leading to interferences of mitochondrial with cytosolic fluorescence. However, transition of cytosolic $\mathrm{Ca}^{2+}$ to mitochondria is slow and it was demonstrated that mitochondrial $\mathrm{Ca}^{2+}$ showed no transient [16]. For these reasons, F400/F510 transients are considered to reflect cytosolic phenomena. Yet, sequestration of Indo-1 in mitochondria potentially provokes a spatial heterogeneity of fluorescence $[16,17]$ and therefore makes it less accurate to estimate the cytosolic $\mathrm{Ca}^{2+}$ levels from F400/F510. Moreover, evaluation of peak cytosolic $\mathrm{Ca}^{2+}$ as a regulator of cardiac function in isolated hearts may be perturbed by both changes of the threshold for cross-bridge interaction due to altered $\mathrm{Ca}^{2+}$ sensitivity of the sarcoplasmic reticulum [18] or changes of the $\mathrm{Ca}^{2+}$ force relationship due to myocardial stretch [19]. Therefore, we expressed $\left[\mathrm{Ca}^{2+}\right]_{i}$ as percentages of the control amplitude of F400/F510 instead of estimating a cytosolic $\mathrm{Ca}^{2+}$ concentration. Accordingly, the amplitude of $\left[\mathrm{Ca}^{2+}\right]_{\mathrm{i}}$ transients has been used in numerous studies to evaluate $\left[\mathrm{Ca}^{2+}\right]_{\mathrm{i}}$ transients as the important modulator of left ventricular devcloped pressurc (and oxygen consumption) in isolated whole hearts [9-11,20-25]. In particular, the amplitude of F400/F510 has recently been used to describe $\left[\mathrm{Ca}^{2+}\right]_{\mathrm{i}}$ transients mediating postextrasystolic potentiation after multiple extrasystolic beats in isolated perfused rat hearts [4].

Another possible limitation arises from reduced fluorescence by time-dependent ultraviolet bleaching and Indo-1 leakage during the experiment. At the end of the experiments, the fluorescence at 400 and $510 \mathrm{~nm}$ was reduced by $10-15 \%$. However, reduced fluorescence does not influence the ratio of fluorescence (F400/F510) and estimation of $\left[\mathrm{Ca}^{2+}\right]_{\mathrm{i}}$ [26]. Yet, reduced fluorescence could be of importance because of variation of autofluorescence between hearts or because of changes of autofluorescence over the experimental period. Such changes could possibly alter the ratio of Indo-1 fluorescence to autofluorescence [27]. However, after attenuation, the range of autofluorescence variation between hearts (less than $0.01 \mathrm{~V}$ ) and the change of autofluorescence over the experimental period (approx. $0.01 \mathrm{~V}$ ) is negligible in our experiments. Another limitation could be caused by fluorescence from the endothelium or the vasculature. However, the contribution of the endothelium and vasculature to Indo-1 fluorescence was shown to be almost negligible in this preparation, as evaluated by bradykinin administration [18]. Finally, interference with the Indo-1 signals with cardiac motion are absent since hearts subjected to zero flow ischemia showed similar fluorescence transients, followed by a gradual increase, despite contractile cessation [14].

\subsection{Curve-fitting procedure and characterization of resti- tution curves}

The mean amplitude of $\left[\mathrm{Ca}^{2+}\right]_{i}$ transients (difference in systolic and diastolic values of F400/F510) and mean left 
ventricular developed pressure of extrasystolic beats were plotted as a function of extrasystolic intervals leading to restitution curves and postextrasystolic restitution curves for $\left[\mathrm{Ca}^{2+}\right]_{i}$ and developed pressure. These curves were described by a monoexponential function [28-30] using a fitting procedure according to a non-linear least-square method. The mathematical equation (1) for the monoexponential function may be written:

$y=A\left(1-\mathrm{e}^{-t / \tau}\right)$

Because of the resting spontaneous activity of rat hearts with atrioventricular block, the pacing protocols could not be performed at longer intervals than $860 \mathrm{~ms}$. Thus, asymptote and time constant $\tau$ of Eqn. (1) could only be estimated. In a more precise way, restitution curves and postextrasystolic restitution curves were characterized and statistically analyzed by two variables: maximal values of fitted curves at the $860 \mathrm{~ms}$ interval (F400/F510 ${ }_{\max }$ and $\mathrm{LVDP}_{\max }$ respectively) and time to reach $75 \%$ of these maximal values (75\%-time). $75 \%$-times were used to describe the slope and thus, time course of curves.

\subsection{Evaluation and statistical analysis}

To determine whether interval-dependent changes of left ventricular developed pressure and interval-dependent changes of the amplitude of $\left[\mathrm{Ca}^{2+}\right]_{\mathrm{i}}$ transients are correlated in isolated whole rat hearts, restitution curves for developed pressure and $\left[\mathrm{Ca}^{2+}\right]_{i}$ were linearized and tested for correlation by linear regression. For this purpose, LVDP
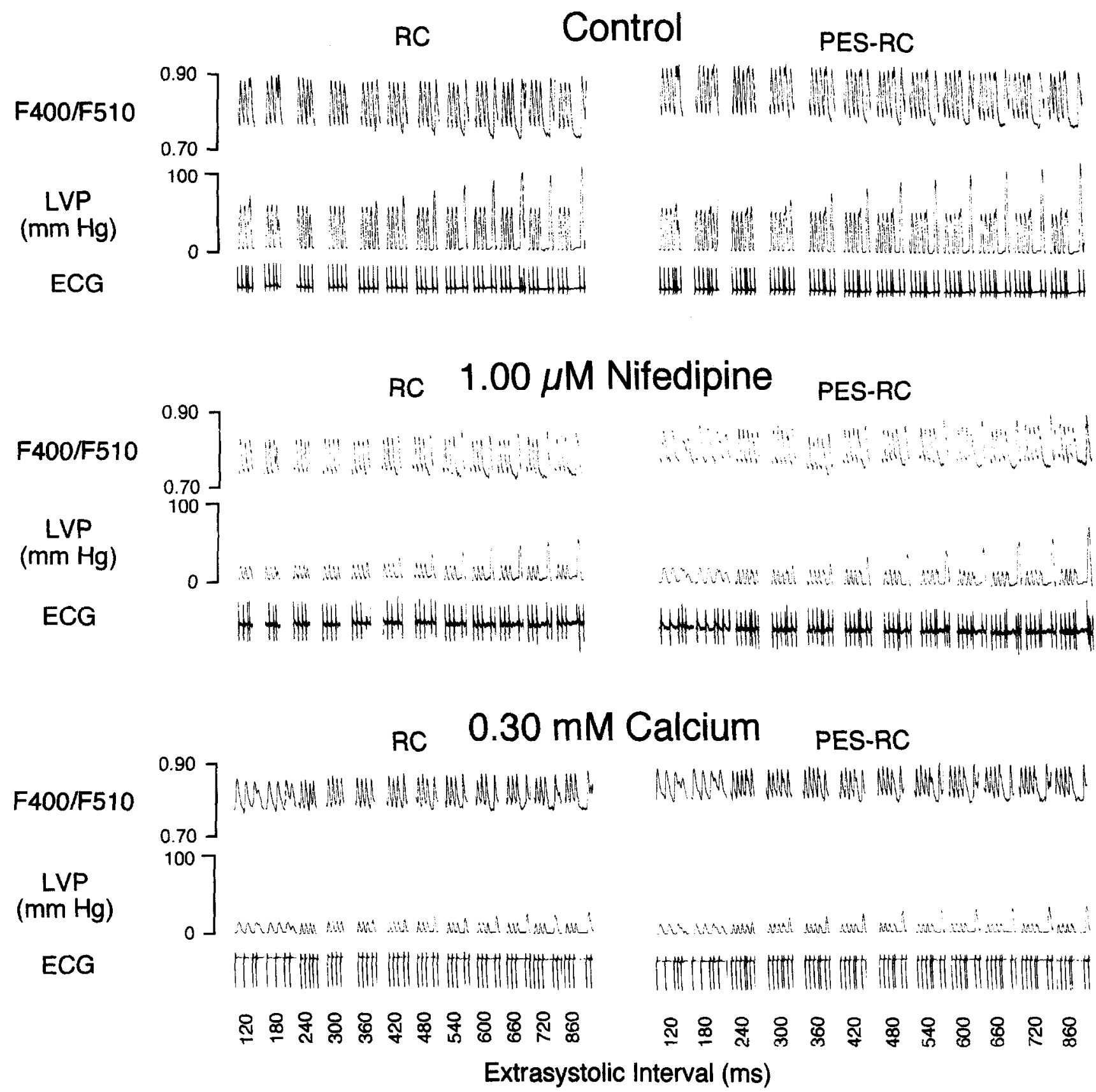

Fig. 1. Original tracings of $\left[\mathrm{Ca}^{2+} l_{i}\right.$ transients (F400/F510), left ventricular pressure (LVP) and the electrocardiogram (ECG) of isolated perfused rat hearts during pacing protocols for restitution curves (RC) and postextrasystolic restitution curves (PES-RC). Three-panel set for control (1.55 mM [Ca $\left.{ }^{2+}\right]_{0}$ ), 1.00 $\mu \mathrm{M}$ nifedipine $\left(1.55 \mathrm{mM}\left[\mathrm{Ca}^{2+}\right]_{0}\right)$ and $0.30 \mathrm{mM}\left[\mathrm{Ca}^{2+}\right]_{0}$. 


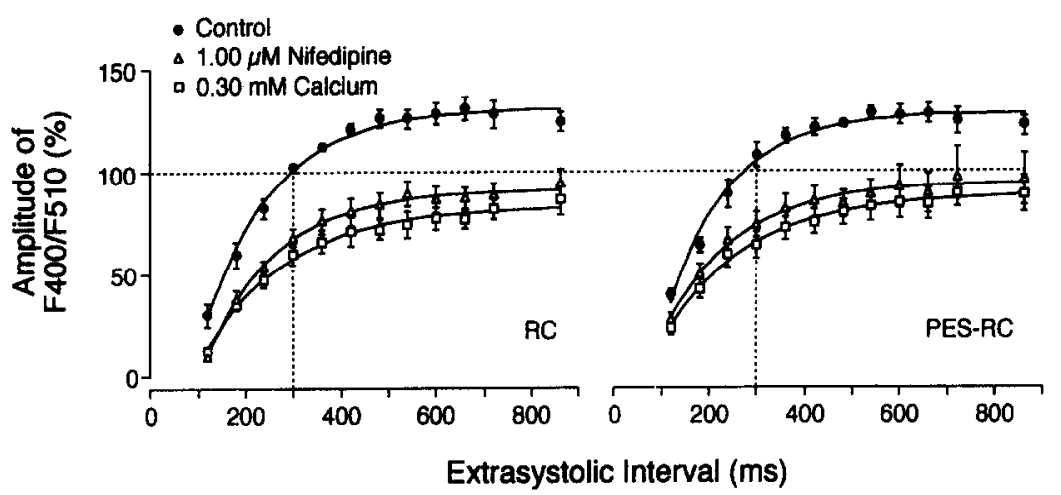

Fig. 2. Restitution curves (RC) and postextrasystolic restitution curves (PES-RC) for $\left[\mathrm{Ca}^{2+}\right]_{\mathrm{i}}$ (amplitude of F400/F510) of isolated perfused rat hearts during control $\left(1.55 \mathrm{mM}\left[\mathrm{Ca}^{2+}\right]_{0}\right), 1.00 \mu \mathrm{M}$ nifedipine $\left.\left(1.55 \mathrm{mM}^{2} \mathrm{Ca}^{2+}\right]_{0}\right)$, and $0.30 \mathrm{nM}\left[\mathrm{Ca}^{2+}\right]_{0}$. Horizontal dashed line shows steady-state amplitude of F400/F510. Vertical dashed lines show steady-state interval between beats ( $300 \mathrm{~ms}$ ). Values are mean \pm s.e.m.; $n=7$ hearts.

and simultaneously measured amplitudes of F400/F510 were linearized according Eqns. (2) and (3) respectively.

$y=-\ln \left(1-\frac{\mathrm{LVDP}}{\mathrm{LVDP}_{\max }}\right)$

$x=-\ln \left(1-\frac{\mathrm{F} 400 / \mathrm{F} 510}{\mathrm{~F} 400 / \mathrm{F} 510_{\max }}\right)$

Then, linearized values of LVDP were plotted against linearized amplitudes of F400/F510 for corresponding extrasystolic intervals. Finally, linear regression was applied to this plot and the resulting correlation coefficient was used to quantify the strength of the relation between LVDP and the amplitude of F400/F510. Because of the sigmoid relationship between developed pressure and amplitudes of F400/F510 [10], direct comparisons of the $75 \%$-times of pressure and F400/F510 were not performed.

To determine whether $\mathrm{Ca}^{2+}$ antagonists or low $\left[\mathrm{Ca}^{2+}\right]_{0}$ change restitution curves and, if so, whether these changes are similar or not, statistical analysis between restitution curves during control perfusion and different concentrations of one $\mathrm{Ca}^{2+}$ antagonist or of low $\left[\mathrm{Ca}^{2+}\right]_{0}$ were performed by repeated measures ANOVA with the Bonferroni $t$-test.

To determine whether postextrasystolic potentiation changes the restitution curves and, if so, whether these changes can be affected by $\mathrm{Ca}^{2+}$ antagonists or low $\left[\mathrm{Ca}^{2+}\right]_{0}$, statistical analysis between restitution curves and postextrasystolic restitution curves was performed by paired $t$-test.

To test for differences between the controls for each perfusion condition (nifedipine, verapamil, diltiazem and low $\left[\mathrm{Ca}^{2+}\right]_{0}$ ) one-way ANOVA with the Bonferroni $t$-test was performed.

All. results are expressed as mean \pm s.e.m. For all statistical analysis, $P$-values of 0.05 or less were considered significant.
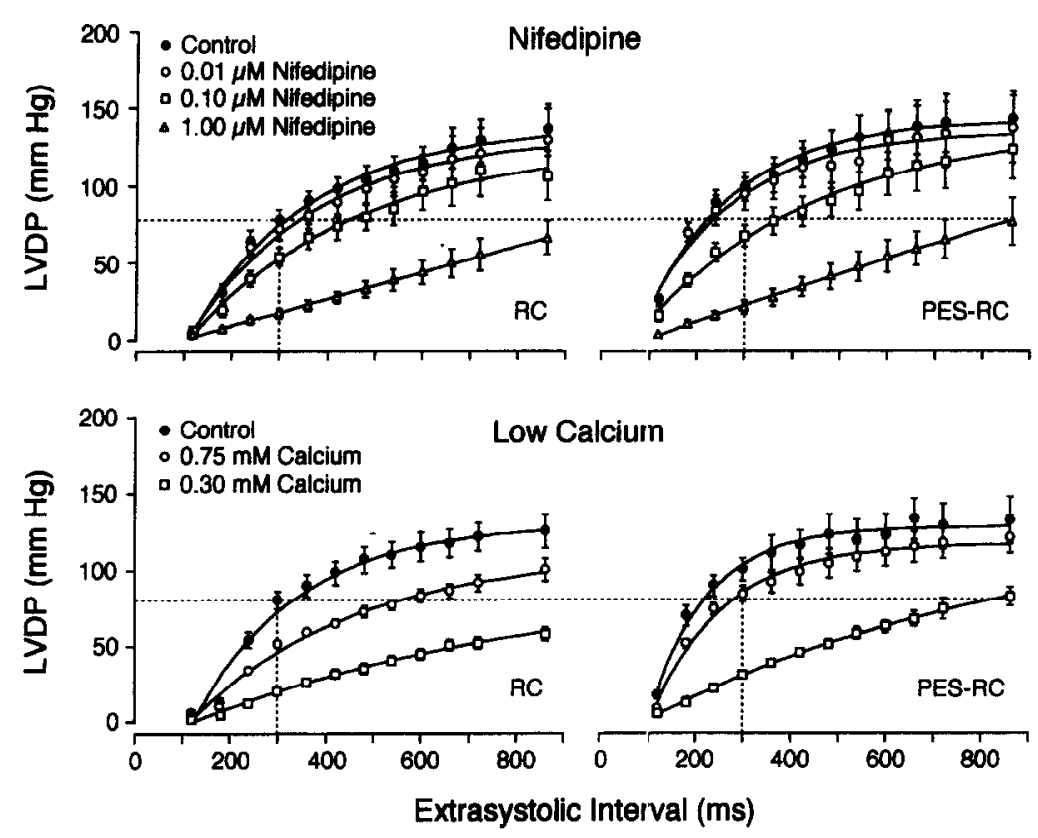

Fig. 3. Restitution curves (RC) and postextrasystolic restitution curves (PES-RC) for left ventricular developed pressure (LVDP) of isolated perfused rat hearts during control $\left(1.55 \mathrm{mM}\left[\mathrm{Ca}^{2+}\right]_{0}\right)$, nifedipine $\left(1.55 \mathrm{mM}\left[\mathrm{Ca}^{2+}\right]_{0}\right)$, and low $\left[\mathrm{Ca}^{2+}\right]_{0}$. Horizontal dashed lines show steady-state LVDP. Vertical dashed lines show steady-state interval between beats $(300 \mathrm{~ms})$. Values are mean + s.e.m.; $n$ numbers see Table 2. 


\section{Results}

\subsection{Restitution curves}

During control perfusion, the pacing protocol for restitution curves led to similar responses of left ventricular developed pressure and amplitudes of $\left[\mathrm{Ca}^{2+}\right]_{i}$ measured by surface fluorometry and Indo-1 in isolated whole rat hearts (original tracings in Fig. 1). Restitution curves for both $\left[\mathrm{Ca}^{2+}\right]_{i}$, assessed by amplitudes of F400/F510 (Fig. 2 left panel), and developed pressure (Fig. 3 controls of left panels) followed a very similar monoexponential pattern. Linearized plotting of developed pressure against amplitudes of F400/F510 and linear regression provided a strong correlation between these two variables (Fig. 4; $r=0.92 ; P<0.01$ ). The controls for each perfusion condition (nifedipine, verapamil, diltiazem and low $\left[\mathrm{Ca}^{2+}\right]_{0}$ ) did not differ from each other among steady-state LVDP ( $P=$ 0.92 ) and among the two characteristic variables for restitution curves, LVDP $_{\max }(P=0.54)$ and $75 \%$-time of LVDP $(P=0.33)$.

\subsection{Effects of $\mathrm{Ca}^{2+}$ antagonists and low $\left[\mathrm{Ca}^{2+}\right]_{o}$ on restitution curves}

During perfusion with $1.00 \mu \mathrm{M}$ nifedipine, the restitution curve for $\left[\mathrm{Ca}^{2+}\right]_{\mathrm{i}}$ was shifted downward (Fig. 2 left panel; original tracings in Fig. 1). This downward shift was expressed by decreased F400/F510 ${ }_{\max }$ (Table 1). However, the slope of the restitution curve for $\left[\mathrm{Ca}^{2+}\right]_{i}$ was not changed during $1.00 \mu \mathrm{M}$ nifedipine. Specifically, the $75 \%$-time of F400/F510 was not significantly changed by $1.00 \mu \mathrm{M}$ nifedipine ( $P=0.91$ vs. control). On the other hand, the restitution curve for pressure was not only shifted downward by $1.00 \mu \mathrm{M}$ nifedipine but had a reduced slope (Fig. 3, left top panel). Specifically, LVDP $P_{\max }$ was decreased by half and the 75\%-time of LVDP was prolonged by $289 \mathrm{~ms}$ (Table 2). During perfusion with a lower nifedipine concentration $(0.10 \mu \mathrm{M}), \mathrm{LVDP}_{\max }$ was less decreased and the $75 \%$-time was less prolonged. Thus, restitution curves for pressure were shifted downward by nifedipine in a concentration-dependent manner (Fig. 3 left top panel). During perfusion with the lowest nifedipine concentration $(0.01 \mu \mathrm{M})$, the restitution curve for pressure was not affected, expressed by unchanged restitution variables, $\mathrm{LVDP}_{\max }(P=0.26$ vs. control) and $75 \%$-time ( $P$ $=0.45$ vs. control).

During perfusion with the two other $\mathrm{Ca}^{2+}$ antagonists, verapamil and diltiazem, restitution curves for pressure

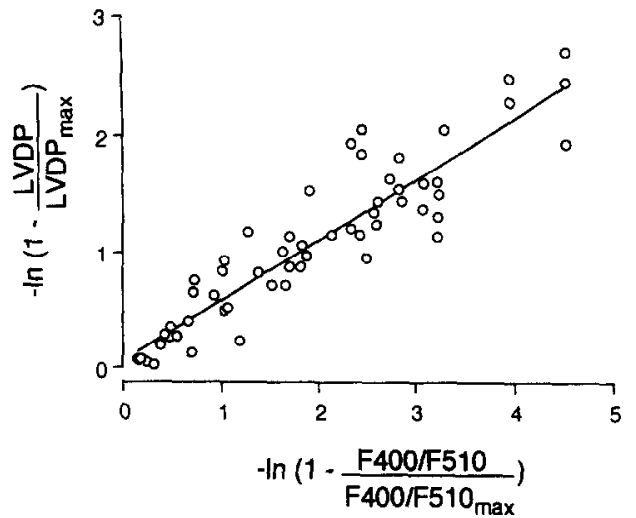

Fig. 4. Relation of linearized left ventricular developed pressure (LVDP) and linearized amplitudes of F400/F510 (simultaneously measured) for corresponding extrasystolic intervals in isolated perfused rat hearts. The continuous line was fitted to the data by linear regression. Slope $=0.52$; $x$-axis intercept $=-0.12$; correlation coefficient $r=0.92(P<0.01)$.

were shifted downward as during nifedipine in a very similar concentration-dependent manner. The characteristic restitution variables were similarly affected by verapamil and diltiazem (Table 2).

During $0.30 \mathrm{mM}\left[\mathrm{Ca}^{2+}\right]_{0}$, the restitution curve for $\left[\mathrm{Ca}^{2+}\right]_{\mathrm{i}}$ was shifted downward as during $1.00 \mu \mathrm{M}$ nifedipine (Fig. 2, left panel; original tracings in Fig. 1, left bottom panel). This downward shift was expressed by decreased F400/F510 ${ }_{\max }$ (Table 1). However, the slope of the restitution curve for $\left[\mathrm{Ca}^{2+}\right]_{\mathrm{i}}$ was not changed during $0.30 \mathrm{mM}\left[\mathrm{Ca}^{2+}\right]_{0}$. Specifically, the $75 \%$-time was not changed by $0.30 \mathrm{mM}\left[\mathrm{Ca}^{2+}\right]_{0}(P=0.40$ vs control; $P=$ 0.42 vs. $1.00 \mu \mathrm{M}$ nifedipine). On the other hand, the restitution curve for pressure was not only shifted downward by $0.30 \mathrm{mM}\left[\mathrm{Ca}^{2+}\right]_{0}$ but had a reduced slope (Fig. 3, left bottom panel). Specifically, LVDP $_{\max }$ was decreased by half and the $75 \%$-time was prolonged by $187 \mathrm{~ms}$ (Table 2). During a higher $\left[\mathrm{Ca}^{2+}\right]_{0}$ concentration (0.75 mM), LVDP $_{\max }$ was less decreased and the $75 \%$-time less prolonged as during a lower concentration of nifedipine $(0.10$ $\mu \mathrm{M})$. Thus, restitution curves for pressure were shifted downward depending on the $\left[\mathrm{Ca}^{2+}\right]_{0}$ concentration.

\subsection{Postextrasystolic restitution curves}

During control perfusion, the slope of the postextrasystolic restitution curve for $\left[\mathrm{Ca}^{2+}\right]_{i}$ was greater than the corresponding restitution curve (Fig. 2, right panel; original tracings in Fig. 1). Specifically, the 75\%-time of the postextrasystolic restitution curve for $\left[\mathrm{Ca}^{2+}\right]_{i}$ was $49 \mathrm{~ms}$ shorter than the $75 \%$-time of the corresponding restitution

Table 1

Effects of nifedipine and low calcium perfusion on characteristic restitution variables of intracellular calcium in isolated perfused rat hearts

\begin{tabular}{|c|c|c|c|c|c|c|}
\hline & \multirow{2}{*}{$\begin{array}{l}n n \\
\text { (hearts) }\end{array}$} & \multirow{2}{*}{$\begin{array}{l}\mathrm{F} 400 / \mathrm{F} 510_{\text {ss }} \\
(\%)\end{array}$} & \multicolumn{2}{|c|}{$\mathrm{F} 400 / \mathrm{F}^{2} 10_{\max }(\%)$} & \multicolumn{2}{|c|}{$75 \%$-time (ms) } \\
\hline & & & $\overline{\mathrm{RC}}$ & $\overline{\text { PES-RC }}$ & $\overline{\mathrm{RC}}$ & PES-RC \\
\hline Control & 7 & $100 \pm 0$ & $134 \pm 7$ & $130 \pm 8$ & $304 \pm 23$ & $255 \pm 9^{\dagger}$ \\
\hline $1.00 \mu \mathrm{M}$ Nifedipine & 7 & $68 \pm 4$ & $86 \pm 7^{*}$ & $86 \pm 7^{*}$ & $306 \pm 11$ & $268 \pm 15^{\dagger}$ \\
\hline $0.30 \mathrm{mM}$ Calcium & 7 & $60 \pm 5$ & $81 \pm 6^{*}$ & $87 \pm 7^{*}$ & $322 \pm 17$ & $291 \pm 15^{\dagger}$ \\
\hline
\end{tabular}

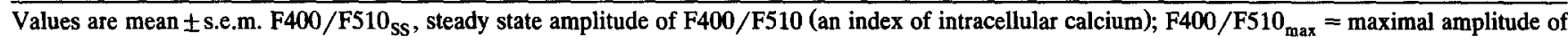
F400/F510 of monoexponentially fitted restitution curves; $75 \%$-time $=$ time to reach $75 \%$ of F400/F510 $\max ;$ RC $=$ restitution curve; PES-RC $=$ postextrasystolic restitution curve; ${ }^{*} P \leq 0.05$ vs. control of corresponding group; ${ }^{\dagger} P \leq 0.05$ vs. corresponding value of RC. 


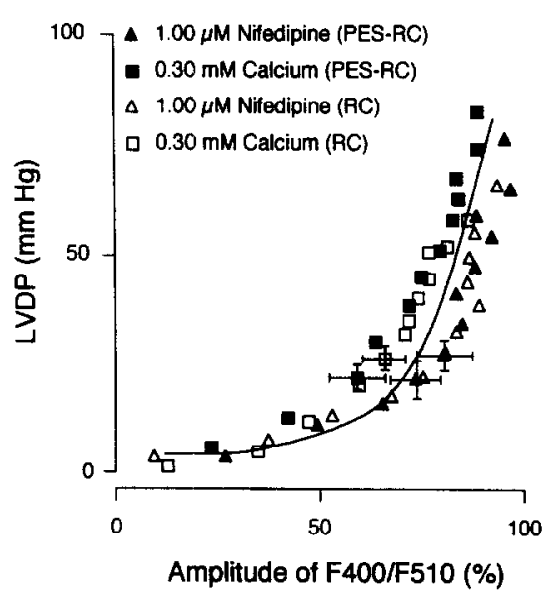

Fig. 5. Relationship between mean left ventricular developed pressure (LVDP) and mean amplitudes of F400/F510 for corresponding extrasystolic intervals in isolated perfused rat hearts during $1.00 \mu \mathrm{M}$ nifedipine and $0.30 \mathrm{mM}\left[\mathrm{Ca}^{2+}\right]_{0}$ for restitution curves (RC) and postextrasystolic restitution curves (PES-RC). Representative SEM for some data are shown (for complete information of variability, see Figs. 2 and 3). The relationship was fitted to the initial part of a single sigmoid curve according to a modified Hill equation [10].

curve (Table 1). However, the plateau of the postextrasystolic restitution curve for $\left[\mathrm{Ca}^{2+}\right]_{\mathrm{i}}$ was not shifted, as seen by unchanged $\mathrm{F} 400 / \mathrm{F}^{2} 10_{\max }(P=0.30$ vs. RC). On the other hand, the postextrasystolic restitution curve for left ventricular pressure was not only steeper than the corresponding restitution curve but also shifted upward (Fig. 3 controls of right panels). The $75 \%$-time of the postextrasystolic restitution curve for pressure was about $100 \mathrm{~ms}$ shorter than the $75 \%$-time of the restitution curve (Table 2). LVDP $_{\max }$ was about $7 \mathrm{mmHg}$ higher for the postextrasystolic restitution curve than for the restitution curve. The controls for each perfusion condition (nifedipine, verapamil, diltiazem and low $\left[\mathrm{Ca}^{2+}\right]_{0}$ ) did not differ from each other among the two characteristic variables for postex- trasystolic restitution curves, LVDP $_{\max }(P=0.39)$ and 75\%-time of LVDP $(P=0.11)$.

During perfusion with $1.00 \mu \mathrm{M}$ nifedipine, the greater slope of the postextrasystolic restitution curve for $\left[\mathrm{Ca}^{2+}\right]_{i}$ was preserved (Fig. 3, right panel). Specifically, the $75 \%$ time of the postextrasystolic restitution curve for $\left[\mathrm{Ca}^{2+}\right]_{\mathrm{i}}$ was $38 \mathrm{~ms}$ shorter than the $75 \%$-time of the corresponding restitution curve during $1.00 \mu \mathrm{M}$ nifedipine. However, the plateau of the postextrasystolic restitution curve for $\left[\mathrm{Ca}^{2+}\right]_{i}$ was not shifted, as seen by unchanged F400/F510 $(P=0.95$ vs. $\mathrm{RC})$. In addition, the increased slope of the postextrasystolic restitution curves for left ventricular pressure was abolished. This abolishment was expressed by very similar $75 \%$-times of postextrasystolic restitution curves and restitution curves for pressure during $1.00 \mu \mathrm{M}$ nifedipine ( $P=0.49$ vs. $R C)$. Nevertheless, the upward shift of the postextrasystolic restitution curve for pressure was preserved during all nifedipine concentrations expressed by higher LVDP $_{\max }$ values of postextrasystolic restitution curves than those of restitution curves. During perfusion with a lower nifedipine concentration $(0.10 \mu \mathrm{M})$, the slope of the postextrasystolic restitution curve for pressure was blunted but still greater than the slope of the corresponding restitution curve. Specifically, the 75\%-time of the postextrasystolic restitution curve for pressure was still $48 \mathrm{~ms}$ shorter than the $75 \%$-time of the corresponding restitution curve. Thus, the greater slope of the postextrasystolic restitution curve for pressure was blunted by nifedipine in a concentration-dependent manner. During the lowest nifedipine concentration $(0.01 \mu \mathrm{M})$, the slope and the shift of the postextrasystolic restitution curve for pressure did not differ from control (75\%-time of LVDP $P=0.89$ vs. control; $\mathrm{LVDP}_{\max } P=0.11$ vs. control).

During perfusion with the two other $\mathrm{Ca}^{2+}$ antagonists, verapamil and diltiazem, effects paralleled those of nifedipine (Table 2). Thus, the greater slope of the postex-

Table 2

Effects of calcium antagonists and low calcium perfusion on characteristic restitution variables of left ventricular developed pressure in isolated perfused rat hearts

\begin{tabular}{|c|c|c|c|c|c|c|}
\hline & \multirow{2}{*}{$\begin{array}{l}n \\
\text { (hearts) }\end{array}$} & \multirow{2}{*}{$\begin{array}{l}\mathrm{LVDP}_{\mathrm{SS}} \\
(\mathrm{mmHg})\end{array}$} & \multicolumn{2}{|c|}{$\mathrm{LVDP}_{\max }(\mathrm{mmHg})$} & \multicolumn{2}{|c|}{$75 \%$-time (ms) } \\
\hline & & & $\mathrm{RC}$ & PES-RC & $\mathrm{RC}$ & PES-RC \\
\hline Control & 5 & $78 \pm 15$ & $123 \pm 15$ & $129 \pm 17^{\dagger}$ & $372 \pm 31$ & $277 \pm 20^{\dagger}$ \\
\hline $0.01 \mu \mathrm{M}$ Nifedipine & 5 & $72 \pm 16$ & $117 \pm 17$ & $123 \pm 20^{\dagger}$ & $381 \pm 39$ & $279 \pm 25^{\dagger}$ \\
\hline $0.10 \mu \mathrm{M}$ Nifedipine & 5 & $48 \pm 14$ & $103 \pm 16$ & $110 \pm 19^{\dagger}$ & $431 \pm 42$ & $383 \pm 40 * \dagger$ \\
\hline $1.00 \mu \mathrm{M}$ Nifedipine & 4 & $19 \pm 4$ & $66 \pm 11^{*}$ & $78 \pm 15^{* \dagger}$ & $661 \pm 10^{*}$ & $654 \pm 13^{*}$ \\
\hline Control & 6 & $73 \pm 17$ & $125 \pm 20$ & $130 \pm 20^{\dagger}$ & $423 \pm 26$ & $303 \pm 13^{\dagger}$ \\
\hline $0.01 \mu \mathrm{M}$ Verapamil & 6 & $67 \pm 27$ & $111 \pm 19$ & $123 \pm 21^{\dagger}$ & $411 \pm 16$ & $301 \pm 18^{\dagger}$ \\
\hline $0.10 \mu \mathrm{M}$ Verapamil & 6 & $39 \pm 13$ & $82 \pm 15^{*}$ & $92 \pm 19^{* \dagger}$ & $496 \pm 30^{*}$ & $411 \pm 39^{* \dagger}$ \\
\hline $1.00 \mu \mathrm{M}$ Verapamil & 6 & $12 \pm 2$ & $31 \pm 6^{*}$ & $39 \pm 8^{* \dagger}$ & $589 \pm 34^{*}$ & $589 \pm 68^{*}$ \\
\hline Control & 5 & $87 \pm 10$ & $151 \pm 9$ & $164 \pm 9^{\dagger}$ & $433 \pm 10$ & $330 \pm 16^{\dagger}$ \\
\hline $0.1 \mu \mathrm{M}$ Diltiazem & 5 & $85 \pm 10$ & $148 \pm 5$ & $155 \pm 9^{\dagger}$ & $430 \pm 13$ & $324 \pm 26^{\dagger}$ \\
\hline $1.0 \mu \mathrm{M}$ Diltiazem & 5 & $64 \pm 17$ & $129 \pm 10^{*}$ & $144 \pm 8^{* \dagger}$ & $511 \pm 13^{*}$ & $416 \pm 26^{* \dagger}$ \\
\hline $10.0 \mu \mathrm{M}$ Diltiazem & 4 & $22 \pm 6$ & $71 \pm 5^{*}$ & $76 \pm 6^{* \dagger}$ & $657 \pm 7^{*}$ & $653 \pm 8^{*}$ \\
\hline Control & 6 & $80 \pm 13$ & $127 \pm 10$ & $133 \pm 13^{\dagger}$ & $409 \pm 20$ & $286 \pm 11^{\dagger}$ \\
\hline $0.75 \mathrm{mM}$ Calcium & 5 & $52 \pm 19$ & $98 \pm 7^{*}$ & $117 \pm 11^{+\dagger}$ & $486 \pm 22^{*}$ & $311 \pm 16^{\dagger}$ \\
\hline $0.30 \mathrm{mM}$ Calcium & 5 & $20 \pm 8$ & $59 \pm 4^{*}$ & $83 \pm 7^{* \dagger}$ & $596 \pm 16^{*}$ & $583 \pm 22^{*}$ \\
\hline
\end{tabular}

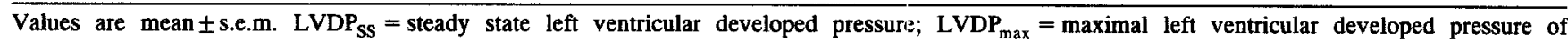
monoexponentially fitted restitution curves; $75 \%$-time $=$ time to reach $75 \%$ of $\mathrm{LVDP}_{\max } ; \mathrm{RC}=$ restitution curve; $\mathrm{PES}$-RC $=$ postextrasystolic restitution curve; ${ }^{*} P \leq 0.05$ vs. control of corresponding group; ${ }^{\dagger} P \leq 0.05$ vs. corresponding value of RC. 
trasystolic restitution curve for pressure was blunted by all $\mathrm{Ca}^{2+}$ antagonists in a concentration-dependent manner. Furthermore, the upward-shift of the postextrasystolic restitution curve for pressure was preserved during all $\mathrm{Ca}^{2+}$ antagonists in all concentrations.

During $0.30 \mathrm{mM}\left[\mathrm{Ca}^{2+}\right]_{v}$, effects paralleled those of $1.00 \mu \mathrm{M}$ nifedipine. The greater slope of the postextrasystolic restitution curve for $\left[\mathrm{Ca}^{2+}\right]_{j}$ was preserved during $0.30 \mathrm{mM}\left[\mathrm{Ca}^{2+}\right]_{0}$ (Fig. 2, right panel). Specifically, the $75 \%$-time of the postextrasystolic restitution curve for $\left[\mathrm{Ca}^{2+}\right]_{i}$ was $31 \mathrm{~ms}$ shorter than the $75 \%$-time of the corresponding restitution curve. However, the plateau of the postextrasystolic restitution curve for $\left[\mathrm{Ca}^{2+}\right]_{\mathrm{i}}$ was not shifted, as seen by unchanged $\mathrm{F} 400 / \mathrm{F} 10_{\text {max }}(P=0.12$ vs. RC). In addition, the increased slope of the postextrasystolic restitution curves for left ventricular pressure was abolished (Fig. 3 right bottom panel). This abolishment was expressed by very similar $75 \%$-times of postextrasystolic restitution and restitution curves for pressure during $0.30 \mathrm{mM}\left[\mathrm{Ca}^{2+}\right]_{\mathrm{o}}(P=0.41$ vs. $\mathrm{RC})$. Nevertheless, the upward shift of the postextrasystolic restitution curve for pressure was preserved during 0.30 and $0.75 \mathrm{mM}$ $\left[\mathrm{Ca}^{2+}\right]_{0}$. This upward shift was expressed by the higher LVDP $_{\max }$ of postextrasystolic restitution curves than LVDP $_{\max }$ of restitution curves.

\section{Discussion}

In the present study, we demonstrate for the first time that the results from isolated muscle preparations about $\left[\mathrm{Ca}^{2+}\right]_{i}$ transients underlying the interval-force relationship can be substantiated in whole hearts. Specifically, we found in isolated perfused rat hearts that restitution curves for both left ventricular developed pressure and amplitudes of $\left[\mathrm{Ca}^{2+}\right]_{i}$ transients, measured by surface fluorometry and Indo-1, followed similar monoexponential functions. Moreover, linearized plotting of left ventricular developed pressure against the amplitude of F400/F510 (an index of $\left[\mathrm{Ca}^{2+}\right]_{\mathrm{i}}$ showed a strong correlation between these two variables (Fig. 4). Thus, interval-dependent changes in left ventricular developed pressure are strongly correlated to interval-dependent changes in the amplitude of $\left[\mathrm{Ca}^{2+}\right]_{i}$ transients in isolated whole rat hearts. This finding is consistent with observations in ferret papillary muscles where interval-dependent changes in contractility were monoexponentially described and linearly correlated with estimated peak concentrations of $\left[\mathrm{Ca}^{2+}\right]_{i}$ assessed by a similar technique with the $\mathrm{Ca}^{2+}$-sensitive photoprotein, aequorin [29].

To discuss our findings in whole rat hearts, we interpreted $\left[\mathrm{Ca}^{2+}\right]_{\mathrm{i}}$ transients as $\mathrm{Ca}^{2+}$ released from the sarcoplasmic reticulum as it has been done in isolated muscle studies $[28,29]$ and other studies in isolated rat hearts $[4,11]$. The reason for this interpretation is that $90 \%$ of the $\left[\mathrm{Ca}^{2+}\right]_{\mathrm{i}}$ transients is composed of $\mathrm{Ca}^{2+}$ released from the sarcoplasmic reticulum [6]. Moreover, in rat myocardium, peculiarly most of the activator $\mathrm{Ca}^{2+}$ circulates between the sarcoplasmic reticulum and myofilaments [31]. In the isolated whole rat heart, we consequently assumed that the interval-dependent $\mathrm{Ca}^{2+}$ release from the sarcoplasmic reticulum caused the interval-dependent changes in the amplitude of $\left[\mathrm{Ca}^{2+}\right]_{\mathrm{i}}$ transients and, thus, caused the interval-dependent changes in developed pressure.

Based on this interpretation, we evaluated the effects of $\mathrm{Ca}^{2+}$ antagonists, low $\left[\mathrm{Ca}^{2+}\right]_{0}$ and postextrasystolic potentiation on restitution curves for $\left[\mathrm{Ca}^{2+}\right]_{\mathrm{i}}$ as effects on interval-dependent $\mathrm{Ca}^{2+}$ release from the sarcoplasmic reticulum. The $\mathrm{Ca}^{2+}$ antagonist nifedipine and low $\left[\mathrm{Ca}^{2+}\right]_{\mathrm{o}}$ both led to similar downward shifts but not to a changed slope of the restitution curve for $\left[\mathrm{Ca}^{2+}\right]_{i}$, in the present study. Specifically, both $1.00 \mu \mathrm{M}$ nifedipine and $0.30 \mathrm{mM}$ $\left[\mathrm{Ca}^{2+}\right]_{0}$ decreased $\mathrm{F} 400 / \mathrm{F} 510_{\max }$ but did not change the $75 \%$-time of the restitution curves for $\left[\mathrm{Ca}^{2+}\right]_{i}$. Thus, low $\left[\mathrm{Ca}^{2+}\right]_{\mathbf{i}}$ (induced by nifedipine or low $\left[\mathrm{Ca}^{2+}\right]_{0}$ ) decreased the maximal $\mathrm{Ca}^{2+}$ release of the sarcoplasmic reticulum but did not essentially change the $\mathrm{Ca}^{2+}$ release kinetics. This interpretation is consistent with the view that the plateau of the restitution curve is determined by the amount of $\mathrm{Ca}^{2+}$ accumulated in the sarcoplasmic reticulum during the preceding $\left[\mathrm{Ca}^{2+}\right]_{i}$ transient and the amount of $\mathrm{Ca}^{2+}$ that remained in the sarcoplasmic reticulum during the preceding $\mathrm{Ca}^{2+}$ release [29]. Moreover, it has been proposed that the time course of the restitution curve is determined by the property of the sarcoplasmic reticulum that $\mathrm{Ca}^{2+}$ taken up is only gradually available for release in the interval between beats [29]. The cause of this gradual availability might be $\mathrm{Ca}^{2+}$ diffusion within the sarcoplasmic reticulum from an "uptake compartment" to a "release compartment" or more likely the recovery from inactivation of the sarcoplasmic reticulum $\mathrm{Ca}^{2+}$ release [3]. However, we suggest that different $\left[\mathrm{Ca}^{2+}\right]_{i}$ concentrations do not affect this gradual $\mathrm{Ca}^{2+}$ availability since both $\mathrm{Ca}^{2+}$ antagonists and low $\left[\mathrm{Ca}^{2+}\right]_{0}$ did not change the slope of the restitution curve for $\left[\mathrm{Ca}^{2+}\right]_{i}$ in the present study.

On the other hand, it may be that postextrasystolic potentiation increased the gradual $\mathrm{Ca}^{2+}$ availability of the sarcoplasmic reticulum since postextrasystolic potentiation increased the slope of the restitution curve for $\left[\mathrm{Ca}^{2+}\right]_{i}$. Specifically, the $75 \%$-time of the postextrasystolic restitution curve for $\left[\mathrm{Ca}^{2+}\right]_{i}$ was $49 \mathrm{~ms}$ shorter than the corresponding $75 \%$-time of the restitution curve (Table 1). Postextrasystolic potentiation has been proposed to depend on additional $\mathrm{Ca}^{2+}$ uptake of the sarcoplasmic reticulum by transmembrane entry of $\left[\mathrm{Ca}^{2+}\right]_{0}$ during a premature beat $[3,28,29,32,33]$. However, different $\left[\mathrm{Ca}^{2+}\right]_{i}$ concentrations were found not to change the $\mathrm{Ca}^{21}$ release kinetics of the sarcoplasmic reticulum in the present study. Therefore, we speculate that a premature beat accelerated the $\mathrm{Ca}^{2+}$ release kinetics of the sarcoplasmic reticulum, maybe by a greater shift of $\mathrm{Ca}^{2+}$ inside the sarcoplasmic reticulum from uptake to release sites as proposed [34,35], or a faster recovery from inactivation of the sarcoplasmic reticulum $\mathrm{Ca}^{2+}$ release. In addition, it seemed that postextrasystolic potentiation increased the $\mathrm{Ca}^{2+}$ availability of the sarcoplasmic reticulum mainly for short extrasystolic intervals after a premature beat. The reason for this suggestion is that postextrasystolic potentiation increased the slope but did not shift the plateau of the restitution curve for $\left[\mathrm{Ca}^{2+}\right]_{i}$ (expressed as unchanged $\mathrm{F} 400 / \mathrm{F} 510_{\max }$ ). One discrepancy is that postextrasystolic potentiation did not 
shift $\mathrm{F} 400 / \mathrm{F} 10_{\max }$ but did shift $\mathrm{LVDP}_{\max }$. It may be that, after long extrasystolic intervals and especially during control conditions, high $\left[\mathrm{Ca}^{2+}\right]_{\mathrm{i}}$ concentrations of postextrasystolic potentiated beats were slightly underestimated by $\mathrm{F} 400 / \mathrm{F} 510$ because of the non-linear relationship between $\mathrm{F} 400 / \mathrm{F} 510$ and true $\left[\mathrm{Ca}^{2+}\right]_{i}$ at high $\left[\mathrm{Ca}^{2+}\right]_{\mathrm{i}}$ concentrations $[14,15]$. Alternatively, it may be that monoexponential curve fitting in this study was not accurate enough to describe actual restitution, which is the sum of several exponential functions if very long extrasystolic intervals are included [30].

Although $\mathrm{Ca}^{2+}$ antagonists have been proposed to alter sarcoplasmic reticulum function [7,8], the effects of nifedipine on the restitution curve and the postextrasystolic restitution curve for $\left[\mathrm{Ca}^{2+}\right]_{\mathrm{i}}$ did not differ from those of low $\left[\mathrm{Ca}^{2+}\right]_{o}$ (Table 1 and Fig. 2). Thus, nifedipine had no effect on the sarcoplasmic reticulum which would have altered $\left[\mathrm{Ca}^{2+}\right]_{\mathrm{i}}$ transients underlying mechanical restitution and postextrasystolic potentiation in the isolated rat heart.

Unexpectedly and in contrast to the restitution curve for $\left[\mathrm{Ca}^{2+}\right]_{\mathrm{i}}$, the restitution curve for pressure was not only shifted downward but also less steep during high concentrations of $\mathrm{Ca}^{2+}$ antagonists (nifedipine, verapamil and diltiazem) and $0.30 \mathrm{mM}\left[\mathrm{Ca}^{2+}\right]_{o}$ (Fig. 3). An explanation for this decreased slope of the restitution curve for pressure may be the sigmoid nature of the relationship between developed pressure and amplitudes of F400/F510 described by a modified Hill equation [10]. During high concentrations of nifedipine and during $0.30 \mathrm{mM}\left[\mathrm{Ca}^{2+}\right]_{0}$, amplitudes of F400/F510 after short extrasystolic intervals fell mainly in the initial range (below $60 \%$ ) of the sigmoid relationship between developed pressure and the amplitudes of F400/F510 (Fig. 5). In this range, changes in amplitudes of F400/F510 lead only to minimal changes in developed pressure. Consequently, the slope of the restitution curves for pressure was decreased although the slope of the restitution curves for $\left[\mathrm{Ca}^{2+}\right]_{\mathrm{i}}$ was preserved during high concentrations of $\mathrm{Ca}^{2+}$ antagonists and low $\left[\mathrm{Ca}^{2+}\right]_{0}$. Similarly, the increased slope of the postextrasystolic restitution curve for pressure was blunted by high concentrations of $\mathrm{Ca}^{2+}$ antagonists and by very low $\left[\mathrm{Ca}^{2+}\right]_{0}$. Evidence for this finding arises from the comparison of the $75 \%$-time of the postextrasystolic restitution curves for $\left[\mathrm{Ca}^{2+}\right]_{i}$ and pressure with the corresponding variables of the restitution curves (Tables 1 and 2). As discussed above for restitution curves during low $\left[\mathrm{Ca}^{2+}\right]_{\mathrm{i}}$, the pressure response can be explained by the sigmoid nature of the relationship between developed pressure and the amplitude of F400/F510. Although amplitudes of F400/F510 were increased by postextrasystolic potentiation after short extrasystolic intervals, they still fell mainly in the initial range (below 60\%) of the sigmoid curve of the relationship between developed pressure and amplitudes of F400/F510 (Fig. 5). In this range, changes in amplitudes of F400/F510 lead only to minimal changes in pressure. Consequently, the slope of the postextrasystolic restitution curves for pressure was decreased although the slope of the postextrasystolic restitution curves for $\left[\mathrm{Ca}^{2+}\right]_{i}$ was preserved during high concentrations of $\mathrm{Ca}^{2+}$ antagonists and low $\left[\mathrm{Ca}^{2+}\right]_{0}$. It appears from Fig. 5 that nifedipine slightly shifted the $\mathrm{Ca}^{2+}$-pressure relationship to the right, suggesting a reduced responsiveness of the myofilaments to $\mathrm{Ca}^{2+}$. However, the comparison of the $\left[\mathrm{Ca}^{2+}\right]_{i}$ transients for similar values of developed pressure revealed no significant difference ( $P=0.18$, ANOVA) among hearts treated with nifedipine or low $\left[\mathrm{Ca}^{2+}\right]_{0}$.

In conclusion, in this study we demonstrate that the results from isolated muscle preparations about $\left[\mathrm{Ca}^{2+}\right]_{i}$ transients underlying the interval-force relationship can be substantiated in whole hearts. According to previous observations in ferret papillary muscles [29], we found in isolated perfused rat hearts that interval-dependent changes in the amplitude of $\left[\mathrm{Ca}^{2+}\right]_{\mathrm{i}}$ transients were strongly correlated to interval-dependent changes in left ventricular developed pressure. $\left[\mathrm{Ca}^{2+}\right]_{i}$ transients in isolated rat hearts could be interpreted as $\mathrm{Ca}^{2+}$ released from the sarcoplasmic reticulum. In our experiments in whole rat hearts, we additionally found that both nifedipine or low $\left[\mathrm{Ca}^{2+}\right]_{0}$ led to similar downward shifts but not to a changed slope of the restitution curve for $\left[\mathrm{Ca}^{2+}\right]_{i}$. Thus, low $\left[\mathrm{Ca}^{2+}\right]_{\mathrm{i}}$ (induced by nifedipine or low $\left[\mathrm{Ca}^{2+}\right]_{0}$ ) decreased the maximal $\mathrm{Ca}^{2+}$ release of the sarcoplasmic reticulum but did not change the $\mathrm{Ca}^{2+}$ release kinetics. On the other hand, we found that postextrasystolic potentiation increased the slope of the restitution curve for $\left[\mathrm{Ca}^{2+}\right]_{\mathrm{i}}$. Thus, postextrasystolic potentiation presumably accelerated $\mathrm{Ca}^{2+}$ release kinetics of the sarcoplasmic reticulum. Furthermore, nifedipine appeared to have no effect on the sarcoplasmic reticulum which would have altered $\left[\mathrm{Ca}^{2+}\right]_{i}$ transients underlying mechanical restitution and postextrasystolic potentiation in the isolated rat heart. However, the effect of postextrasystolic potentiation on pressure was blunted by high concentrations of $\mathrm{Ca}^{2+}$ antagonists and very low $\left[\mathrm{Ca}^{2+}\right]_{0}$.

\section{Acknowledgment}

Christian E. Zaugg was supported by the Swiss National Science Foundation. Peter T. Buser was supported by a career development grant (SCORE) from the Swiss National Science Foundation. This study was supported in part by the George D. Smith Fund.

\section{References}

[1] Braveny P, Kruta V. Dissociation de deux facteurs: restitution et potentiation dans l'action de l'amplitude de la contraction du myocarde. Arch Int Physiol Biochem 1958;66:633-652.

[2] Hoffman BF, Bindler E, Suckling EE. Postextrasystolic potentiation of contraction in cardiac muscle. Am J Physiol 1956;185:95-102.

[3] Bers DM. Excitation-contraction coupling and cardiac contractile force. Dordrccht: Kluwers Academic Press, 1991;155-170.

[4] Kojima S, Wu ST, Wikman-Coffelt J, Parmley WW. Intracellular calcium transients in potentiated contractions induced by multiple extrasystolic beats in isolated perfused rat hearts. Cell Calcium 1994;16:219-226.

[5] Wohlfart B, Elzinga G. Electrical and mechanical responses of the intact rabbit heart in relation to the excitation interval. A comparison with the isolated papillary muscle preparation. Acta Physiol Scand 1982;115:331-340.

[6] Wier WG. Cytosolic $\left[\mathrm{Ca}^{2+}\right]$ in mammalian ventricle: dynamic control by cellular process. Annu Rev Physiol 1990;52:467-485.

[7] Bayer R, Hennekes R, Kaufmann R, Mannhold R. Inotropic and electrophysiological actions of verapamil and D600 in mammalian 
myocardium. I. Pattern of inotropic effects of the racemic compounds. Naunyn Schmiedebergs Arch Pharmacol 1975;290:49-68.

[8] Zucchi R, Limbruno U, Ronca-Testoni S, Yu G, Galbani P, Ronca G, Effects of verapamil, gallopamil, diltiazem and nifedipine on sarcoplasmic reticulum function in rat heart. Cardioscience 1992;3:167-172.

[9] Wikman-Coffelt J, Stefenelli T, Wu ST, Parmley WW, Jasmin G, $\left[\mathrm{Ca}^{2+}\right]_{\mathrm{i}}$ transients in the cardiomyopathic hamster heart. Circ Res 1991;68:45-51.

[10] Kojima S, Wu ST, Wikman-Coffelt J, Parmley WW. Acute effects of ethanol on cardiac function and intracellular calcium in perfused rat heart. Cardiovasc Res 1993;27:811-816.

[11] Kojima S, Wikman-Coffelt J, Wu ST, Parmley WW. Nature of intracellular calcium transients during ventricular fibrillation and quinidine treatment in perfused rat hearts. Am J Physiol 1994;266:H1473-H1484.

[12] Perrin DD, Sayce IG. Computer calculation of equilibrium concentration in mixtures of metal ions and complexing species. Talanta 1967;14:833-842.

[13] Halpern MH. The dual blood supply of the rat heart. Am J Anat 1957;101:1-16.

[14] Wagner S, Wu ST, Parmley WW, Wikman-Coffelt J. Influence of ischemia on $\left[\mathrm{Ca}^{2+}\right]_{\mathrm{i}}$ transients following drug therapy in hearts from aortic constricted rats. Cell Calcium 1990;11:431-444.

[15] Wikman-Coffelt J, Wu ST, Parmley WW, Mason DT. Angiotensin II and phorbol esters depress cardiac performance and decrease diastolic and systolic $\left[\mathrm{Ca}^{2+}\right]_{i}$ in isolated perfused rat hearts. Am Heart J 1991;122:786-794.

[16] Miyata H, Silverman HS, Sollott SJ, Lakatta EG, Stern MD, Hansford RG. Measurement of mitochondrial free $\mathrm{Ca}^{2+}$ concentration in living single rat cardiac myocytes. Am J Physiol 1991;261:H1123H1134.

[17] Williford DJ, Sharma VK, Korth M, Sheu SS. Spatial heterogeneity of intracellular $\mathrm{Ca}^{2+}$ concentration in nonbeating guinea pig ventricular myocytes. Circ Res 1990;66:241-248.

[18] Wikman-Coffelt J, Wu ST, Parmley WW. Intracellular endocardial calcium and myocardial function in rat hearts. Cell Calcium 1991;12:39-50.

[19] Fabiato A, Fabiato F. Dependence of the contractile activation of skinned cardiac cells on the sarcomere length. Nature (Lond) 1975;256:54-56.

[20] Auffermann W, Stefenelli T, Wu ST, Parmley WW, Wikman-Coffelt J, Mason DT. Influence of positive inotropic agents on intracellular calcium transients. I. Normal rat heart. Am Heart J 1989;118:1219-1227.

[21] Wu ST, Kojima S, Parmley WW, Wikman-Coffelt J. Relationship between cytosolic calcium and oxygen consumption in isolated rat hearts. Cell Calcium 1992;13:235-247.

[22] Lorell BH, Apstein CS, Cunningham MJ, et al. Contribution of endothelial cells to calcium-dependent fluorescence transients in rabbit hearts loadcd with Indo 1. Circ Rcs 1990;67:415-425.

[23] Camacho SA, Figueredo VM, Brandes R, Weiner MW. Ca(2+)dependent fluorescence transients and phosphate metabolism during low-flow ischemia in rat hearts. Am J Physiol 1993;265:H114-H122.

[24] Figueredo VM, Brandes R, Weiner MW, Massie BM, Camacho SA. Cardiac contractile dysfunction during mild coronary flow reductions is due to an altered calcium-pressure relationship in rat hearts. J Clin Invest 1992;90:1794-1802.

[25] Stefenelli T, Wu ST, Parmley WW, Mason DT, Wikman-Coffelt J. Influence of positive inotropic agents on intracellular calcium transients. II. Cardiomyopathic hamster hearts. Am Heart J 1989;118: 1228-1236.

[26] Wahl M, Lucherini MJ, Gruenstein E. Intracellular $\mathrm{Ca}^{2+}$ measurement with Indo-1 in substrate-attached cells: advantages and special considerations. Cell Calcium 1990;11:487-500.

[27] Fralix TA, Heineman FW, Balaban RS. Effects of tissue absorbance on NAD(P)H and Indo-1 fluorescence from perfused rabbit hearts. FEBS 1990;262:287-292.

[28] Yue DT, Burkhoff D, Franz MR, Hunter WC, Sagawa K. Postextrasystolic potentiation of the isolated canine left ventricle. Relationship to mechanical restitution. Circ Res 1985;56:340-350.

[29] Wier WG, Yue DT. Intracellular calcium transients underlying the short-term force-interval relationship in ferret ventricular myocardium. J Physiol 1986;376:507-530.

[30] Cooper IC, Fry CH. Mechanical restitution in isolated mammalian myocardium: species differences and underlying mechanisms. J Mol Cell Cardiol 1990;22:439-452.

[31] Bers DM. Ca influx and sarcoplasmic reticulum $\mathrm{Ca}$ release in cardiac muscle activation during postrest recovery. Am J Physiol 1985;249:H366-H381.

[32] Wood EH, Hepner RL, Weidmann S. Inotropic effects of electrical currents. Circ Res 1969;24:409-445.

[33] Nilius B, Schuttler K, Boldt W. [Properties of the premature extrasystolic action potentials in the rabbit atrial myocardium]. Acta Biol Mcd Gcr 1981;40:275-286.

[34] Ketker JP, Ruigrok TJC, Nieuwenhuijs HS, Borst C, Meijler FL. Postextrasystolic potentiation: influence of calcium and verapamil in rat and rabit hearts. Eur Heart J 1985;6:532-538.

[35] De Mello WC. Post-extrasystolic potentiation; effect of Ca, histamine, caffeine and epinephrine. Arch Int Pharmacodyn Ther. 1977;230:235-244. 